\title{
Indian Versus Canadian Health Care Systems and Policy: A Review Based on Barr's Model of Health Care Governance
}

\author{
Agarwal $\mathbf{A}^{1}$, Tofighi $\mathrm{T}^{1}$, Chawla $\mathrm{K}^{1}$ and Mondal $\mathrm{T}^{2 *}$ \\ ${ }^{1}$ McMaster University, Hamilton, Canada \\ ${ }^{2}$ McMaster Children's Hospital, McMaster University, Hamilton, Canada
}

\begin{abstract}
The health care systems of India and Canada are founded on different principles, and continue to be shaped by social factors, economic influences, population demographics, and health care policies. In comparing the primary challenges of the Indian and Canadian health care systems, this review examines the broader context of private and public health care. This review uses a structured, transparent, and unique approach to analyze the available literature in the field of public health, based on the five primary aspects of health policy encompassed within Barr's framework. In consideration of published literature and reports, this review explores how Canada's one-tier system continues to experience issues relating to waiting times and specialist access. It also identifies challenges in India's two-tier health care system, ranging from an overdependence on the private system to a significant lack of regulation on a federal scale, leading to shortcomings in the quality of care and accountability. In considering the literature and assessments of health care within Barr's framework, this study makes several recommendations which encompass the optimization of health care systems to service Canada's aging population and India's expanding young population.
\end{abstract}

Keywords: India; Canada; Barr's model; Health policy; Health care delivery

\section{Introduction}

The Canadian health care system is primarily administered and delivered by provinces and territories, with public health insurance plans covering certain medical services through a first-dollar, one-tier public approach $[1,2]$. First-dollar payment refers to the full coverage of medically-necessary hospital and physician services by the government of Canada. Under the Canada Health Act, user charges and extra billing are prohibited when such services are offered [3]. In comparison, the Indian health care system focuses on a "health for all" approach based on the National Health Policy (NHP) of 1983. Additionally, the private sector plays a vital role in health care delivery in India, and accounts for roughly $80 \%$ of total health care spending $[4,5]$. Unlike Canada, the health care system in India is structured as a two-tier system in which the quality of the health care services received is directly correlated with the financial status of an individual [6].

The purpose of this review is to: a) provide a brief overview of government-based policies concerning health care education, regulation, financing, and delivery in Canada and India, and; b) provide analyses and recommendations on health care mechanisms in the two countries with an evidence-based approach.

\section{Methods}

This review utilizes an objective and structured approach to analyzing available evidence, with the ultimate goal of minimizing bias and addressing multiple facets of the health care systems present in the two countries. The study first assessed and compared governing policies and primary strengths and challenges faced by the Indian and Canadian health care systems. This data was collected within Nicholas Barr's framework, which encompasses five primary means through which governments influence health care administration, financing and delivery: the provision of information regarding the health care system and available services; regulation of the delivery and conduct of providers and insurers; transfer of income to citizens for health care purchase; financing of health care provision collectively via public funds; and production and delivery of health care services publicly [7].
The first criterion was specifically assessed on the basis of information available to the public which has the potential to guide patient decisionmaking. A variety of databases were used to collect pertinent data and statistics, including the World Health Organization (WHO), Ministry of Health and Family Welfare of the Government of India, and Health Canada.

\section{Results}

The Canadian and Indian health care systems and governance mechanisms have been explored here with an emphasis on: a) primary governing policies; b) private versus public division of health care administration and delivery; and c) an evaluation of the mechanisms involved in health care administration and delivery based on Barr's model.

\section{Primary governing policies}

The Canada Health Act of 1984 serves to empower the federal government with financial and administrative responsibility, and the provincial and territorial governments with the responsibility of free and universal health care provision [1]. The act was established in order to ensure the accessibility of health care services across all financial classes in order to protect, promote, and restore the state of health for Canadian residents [8]. It encompasses five primary aspects: public administration, comprehensiveness, universality, portability, and accessibility. Furthermore, it primarily serves to uphold public insurance through non-profit organization, cover medically necessary

*Corresponding author: Dr. Tapas Mondal, Department of Pediatrics, McMaster University, 1280 Main Street West, Hamilton, ON, L8S 4K1, Canada, Tel: (905) 521-2100 x75259; E-mail: mondalt@mcmaster.ca

Received August 24, 2013; Accepted September 30, 2013; Published October 02, 2013

Citation: Agarwal A, Tofighi T, Chawla K, Mondal T (2013) Indian Versus Canadian Health Care Systems and Policy: A Review Based on Barr's Model of Health Care Governance. Health Care Current Reviews 1: 103. doi: 10.4172/2375-4273.1000103

Copyright: (C) 2013 Agarwal A, et al. This is an open-access article distributed under the terms of the Creative Commons Attribution License, which permits unrestricted use, distribution, and reproduction in any medium, provided the original author and source are credited. 
fees incurred by residents, ensure national equality in health coverage regardless of the location of residence, eliminate extra billing and user fees through regulation of health insurance plans, and provide all residents with access to insured health resources without any charge regardless of economic circumstances and personal identifiers [8].

Similarly, the NHP marked a major revolution in the Indian health care system with its introduction, establishing a new form of health care administration and redefining acceptable standards of good health $[9,10]$. More specifically, the policy was initiated with the goal of increasing access to the decentralized public health care system, as well as facilitating symmetry and integration of health care institutions through the establishment of a novel infrastructure [10]. It was also intended to meet the need for a greater investment in health services through increased governmental financial aid, as well as to optimize health care service delivery by refining the national health administration at the state level [10]. Recent vital goals of the NHP have been to eliminate polio and leprosy, diseases that have now been largely eradicated [10]. Other aims include minimizing diseases such as malaria, dengue and filaria/microfilaria, as well as an increased provision of clean drinking water and reductions in malnutrition and infant mortality rates [10]. The government is also aiming to increase its health expenditure from $0.9 \%$ to $2 \%$ of the GDP [11].

\section{Private versus public division of health care service administration and provision}

Primary challenges and successes: In parallel with the public system established by India's NHP, there exists a private sector which accounts for approximately $80 \%$ of total health care spending by urban and rural households $[4,12]$. Despite financial gaps and inconsistencies in health care quality within the private sector, studies have found that it has consistently been the more heavily utilized system across all social classes, particularly due to cited "misgivings and scepticisms" over the public sector [13]

The Indian private health care system consists of two primary forms of services: organized and informal. The former is characterized by registered physicians and private hospitals, while the latter is largely composed of healers and health care providers without registered qualifications $[14,15]$. Within the context of a competitive market, the quality and cost of India's private health care system is influenced by the efficiency and capacity of operating services [16]. As such, economic and social factors have moulded health care in India with significant influence on both the quality and financial accessibility of services [16]. Although the private health care sector is viewed as the more efficient alternative to public health care, quantitative studies have identified that it bears an acute lack of physician accessibility, with forty trained physicians providing health care to 100,000 individuals [12] relative to Canada's ratio of 2.4 physicians/1,000 individuals in 2012 [17]. Moreover, physicians working in the private health care system are known to prescribe a greater number of drugs and injections than physicians in the public sector, and a higher incidence of reported cases of unnecessary surgical interventions such as hysterectomies has been noted as well $[15,18,19]$. The challenge in the private sector lies in attaining the correct balance between service optimization, and cost to the public. As $82 \%$ of private health care in India is primarily financed out-of-pocket, approximately $8 \%$ of family income is spent on health care $[16,20]$. Studies in the rural region of Karnataka suggest that those living in poverty (below the poverty line) tend to visit the hospital in only $21 \%$ of all reported incidences, suggesting a lack of health care accessibility for this cohort [21]. Those living in poverty have generally been found to finance their health care through interactions with pawnbrokers, moneylenders, and family support systems, leaving them at an even higher risk of poor access to health care and overall financial instability [21].

In contrast, the Canadian health care system is publicly funded by provincial and territorial health insurance plans, and has been the subject of discussion and debate since its establishment [1]. While the two-tier health system in India has been criticized for the lack of accessibility of the same services to those living in poverty, the publicly funded one-tier system of health care in Canada has experienced inefficiencies pertaining to waiting times, shortage of doctors, and inconsistencies pertaining to overall health care delivery coverage [22-24]. In particular, the Canadian public health system faces challenges in providing timely access to services such as specialist consults, family doctor visits, and surgery [25]. However, the system has its advantages as well, particularly with regards to the quality of health care provision and the accessibility of services without discrimination. In fact, in the 2005 Ipsos-Reid Health Report Card, $54 \%$ of the participants in a survey graded the health care system as an 'A' for easy access to emergency facilities, $62 \%$ thought the same for family doctor accessibility, and 65\% shared this degree of content for walk-in clinic availability and accessibility [26]. Much like the Indian health care system's advancements in eliminating polio and leprosy, the Canadian health system has also excelled in the field of preventative medicine, with a large focus on disease prevention [27]. Furthermore, few cases of superfluous surgeries or administration of injections have been documented to date [28].

\section{Barr's model: Canadian and Indian health care system analyses}

The contrast between the Indian and Canadian health care systems is large, with the two systems differing from each other in various respects. The following analysis of Barr's model has been conducted on the basis of federal-level structures and services, and has largely excluded services specific to localities or states/provinces. This approach has been taken to address different facets of health care administration, financing, and delivery within the context of the two countries on the basis of the criteria outlined in the Methods section of this study.

Provision of information: Through the provision of information to patients and consumers, the general public can be informed regarding available health care services and educated on relevant health-related issues, both of which may serve as guiding factors in patient decisionmaking. The Canadian federal government provides several forms of statistical information, but does not emphasize the provision of such information to patients and consumers, despite several provincial and territorial governments making efforts towards doing so. Health Canada is associated with informational resources like Statistics Canada, Federal Health Partner's Secretariat and Canadian Institute for Health Information (CIHI), the Public Health Agency of Canada (PHAC), and the First Nations and Inuit Health Branch. It provides comprehensive information on quality of health care (i.e.: Health Indicator reports), medical care, and mortality and morbidity rates of various diseases [29]. However, while this statistical data allows one to track change and progress within health care delivery, it does not influence patient choices directly or specifically.

In India, the federal government facilitates information provision via different centres and departments under the Ministry of Health and Family Welfare [30]. For example, the ministry's Department of Health and Family Welfare provides a list of health care services and addresses the diseases it encompasses [30]. However, while this list is accessible to 
the public, it does not directly guide patient decision-making, informing patients only very generally regarding programs and services that are accessible to them. The Central Bureau of Health Intelligence (CBHI), the national nodal organization for health intelligence, is responsible for the preparation and distribution of reports which contain statistics and findings on areas such as general population-based health information [31]. While it provides information on health care services and overall health trends within the country, the CBHI does not seem to directly guide patient decision-making either, emphasizing statistics but not patient education on health care alternatives. It is important to consider the roles of the relatively low literacy and health care-seeking behaviour rates as a whole with this demographic, which are likely to influence both the means and the degree to which governments are able to provide information relevant to patient decision-making.

The lack of ability or initiative to disclose information to the public makes health care markets inept at functioning effectively [32]. It is evident that the health care systems in India and Canada both lack national-level organizations or initiatives focused on patient and general public education and awareness.

Regulation of delivery and conduct of providers and insurers: The regulation of health care involves the monitoring and control of health care service delivery specifically, and does not pertain directly to the financing or funding aspects of these services. The Canadian federal government regulates the delivery of health care services and the conduct of health care providers primarily through the Canada Health Act [33]. The federal government is responsible, as per the Food and Drug Act, for health protection and regulation in terms of securing the safety of drugs, foods, and medical devices [33]. In addition, under the British North America (BNA) Act, provinces are given the responsibility of health care regulation and remuneration [34]. An issue in terms of federal regulation and monitoring over provincial health care administration and delivery is the lack of universality in the definition of "medically necessary" services between provinces, which is defined by provincial governments with correspondence to provincial medical and dental professional bodies [35]. The challenge is to develop a more unified set of insured health care services across all Canadian jurisdictions [36].

Several documents aid the Indian government in regulating the delivery of health care nationally. The Indian Public Health Standards (IPHS) establishes the standards that health centres are expected to adhere to nationally [37]. Despite not constituting legislature and, thereby, not obligating centres to meet the set standards legally, these standards are meant to provide a regulatory guideline. While the IPHS has been influential in the regulation of publicly-funded community health centres, the lack of legal grounding has led to these centres being ill-equipped and over-crowded [38]. In addition, legislature such as the Indian Medical Council Act facilitates the regulation of ethical conduct federally, in both the private and public sectors [30,39]. However, despite having legal grounding, these regulations lack sound enforcement at the state and federal levels [38]. The lack of maintenance of standards for private medical services has also proven to be problematic for the Indian health care system. This, along with opposition from powerful lobbies which prevent the government from effectively regulating the private sector, has led to concerns such as the over-prescription of drugs, recommendation of unnecessary diagnosing and treatments, and an overall failure to provide appropriate information to patients [40].

It is evident that both the Indian and Canadian health care systems have policies in place at the national level, in order to regulate the services which address the countries' health care needs. However, inadequacies in the enforcement of these policies currently exist, limiting the scope of their impact.

Transferring of income to citizens: The transfer of income to citizens for health care purchases is not in place as a major mechanism within the Canadian health care system. However, large private companies sometimes offer health savings accounts, which allow individuals to evade taxes on a certain portion of their financial resources set aside and allotted for expenditure on allowable health care needs over the course of the year [41]. In India, while numerous programs are financed by the federal government (discussed in the following section), transferring of income to citizens for health care purchases does not seem to be a primary health care strategy.

Financing of health care provision via public funds: Financing of health care in Canada occurs predominantly in the form of cash and tax point transfers through the federal government [42]. In addition to funds pooled via general taxation and health insurance plans, out of pocket payments and donations for charity organizations constitute a notable avenue of financial resources for health care provision $[43,44]$. Cash and tax transfers are provided federally to provinces and territories to support health care services through the Canada Health Transfer. Transfer payments are based on a combination of tax transfer and cash contributions [43,44]. Equalization payments are also paid to less prosperous provinces and territories [44]. Since the majority of private health insurance plans are sponsored by employers, unions, or professional organizations, the protection of those people who are not covered by employment-related health insurance plans is a challenge that is yet to be addressed [36].

Public health care services in India are financed through taxation and national income, both federally and at the state level [45]. Rashtriay Swasthaya Bima Yojna represents the government-financed federal insurance scheme employed to insure families living in poverty and reduce out-of-pocket medical expenses, and this scheme is mirrored by state-level insurance plans [46,47]. In servicing the population below the poverty line, which constitutes approximately 300 million individuals as of 2012, the scheme has been noted as an exemplar of how stakeholder cooperation, the use of a business model, empowerment of beneficiaries, flexibility and efforts towards standardization can lead to a successful government program [47]. Implemented from 1997, the government-based Jeevandai Arogya Yojna program has also been established to financially support individuals below the poverty line with services such as treatment of serious cardiac, renal and neural diseases [48]. In terms of sources of financing, while state government budgets constituted over $80 \%$ of the public financing of the health care as of 2003, the Union government only constituted $12 \%$ and local governments only constituted $8 \%$, capturing an imbalance. Currently, approximately $10 \%$ of the total public health budget is externally financed, in contrast to $1 \%$ prior to the Structural Adjustment loan from the World Bank and loans from other agencies [38]. Private financing places a heavy burden on health care consumers, as it is primarily financed out-of-pocket, especially for hospitalisations. Social or private insurance schemes constitute a minor aspect of private health care financing in the Indian nation [38].

Public health care service financing mechanisms are present in both countries through government and policy-based infrastructures. An ongoing challenge in the Indian health care system is reducing out-of-pocket expenditure, particularly within the private sector, while additional coverage for those without employment-based health insurance plans is an area which remains largely unaddressed in Canada. 
Production and delivery of health care services publicly: The Canadian federal government does not prioritize the direct facilitation of health care service production or delivery publicly. It only provides direct service to select groups such as First Nations, Inuit, Canadian Forces, Royal Canadian Mounted Police, veterans, federal penitentiary inmates, and refugee claimants. Services under the Canada Health Act and Medicare are primarily provincially-delivered [1]. Health care is generally publicly administered but is based on a model which promotes physician autonomy from upper-level regulatory bodies in terms of the services they deliver [49].

On the other hand, the federal government of India places a heavy emphasis on public health care provision, while state-funded Primary Health Centres, Community Health Centres, and Urban Health Centres provide public health care services on a subsidized out-ofpocket fee basis [50]. The private sector contributes to the production and delivery of health care services significantly as well, but places a heavier financial burden on patients due to a lack of cost subsidization [50].

\section{Discussion}

This review reports several findings: a) large differences exist between the one-tier Canadian health care system and the two-tier Indian health care system, the former primarily public in nature and facing more challenges in terms of timely access to care, and the latter being primarily private in nature and facing more challenges in terms of financial limitations and service accessibility; b) the NHP and the Canada Health Act play significant roles in federally arranging health care for all residents within the jurisdiction; c) despite providing various forms of statistical data, the governing bodies in the two countries do not convey to the public sufficient medical information that would direct patient decision-making with regards to healthcare options; d) while both countries have policies and professional bodies in place for the regulation of consistent health care within their respective jurisdictions, the Canadian system lacks uniformity across provinces in defining the services that are considered "medically-necessary", whereas the Indian system lacks legal grounding and implementation; e) transferring of income directly to individuals is not a significant systemic mechanism in either health care system; f) while the Indian health care system involves greater out-of-pocket expenditures due to its predominantly private nature despite a significant portion of population being belowthe-poverty-line, the Canadian health care system provides public insurance coverage to all residents, but does not have any compensatory mechanisms in place for those without additional employment-based health care insurance; g) while health care provision is predominantly provincial in Canada except services pertaining to special cohorts, the Indian health care system involves significant provision of services on a federal level.

When making recommendations regarding future actions and improvements in both the Canadian and Indian health care systems, it is important to consider the influence of demographic distribution. As India's health care system must meet the needs of a young demographic, vaccination programs are essential to uphold, whereas Canada must focus on a more long-term preventative model of health care to service the aging population.

Presently, a mistrust and lack of assurance exists towards public health care in India, and an effort must be made to dedicate increased funding towards improving public health care facilities and services in order to address the accessibility and quality of public medical care. From a medically-oriented perspective, studies further suggest that the private sector could improve long-term accessibility and quality of health care by investing more in preventative strategies and policies which encourage unified national goals including immunization [51,52]. These preventative strategies have the potential to improve general health care while reducing the overall burden on the system associated with the treatment of commonly preventable illnesses. To address the growing issues associated with private physicians prescribing risky and unnecessary medications that compromise the quality of health care services, the launching of a national awareness training program for both physicians and patients regarding medical procedures and drug prescriptions has been suggested in the past [15]. Finally, literature also suggests that key policies be introduced to improve the quality and accessibility of the private health sector, including but not limited to enacting policies that control the sales of unnecessary drugs, and that support government-subsidized health insurance [15].

The High-Level Expert Group on Universal Health Coverage, organized by the Planning Commission of India in October 2010, represents a major step in the direction towards equitable health care access for India. With specific recommendations in six critical areas - Health Financing and Financial Protection, Health Service Norms, Human Resources for Health (HRH), Community Participation and Citizen Engagement, Access to Medicines, Vaccines and Technology, and Management and Institutional Reforms - the group has identified the elements necessary to strengthen the capacity of the health care system, and will be relying heavily on adequate human resources and collaboration with currently-existing committees such as the Village Health Committees and Health and Sanitation Committees to ensure the success of its goals [53]. The Government of India's Twelfth Five-Year Plan represents another move towards inclusive growth with consideration to employment and livelihood, demographics, agriculture, health and education, among other factors. Particularly with regards to health, the Plan has focused on additional resource allocation to address infant and maternal mortality rates, institutional delivery, full immunization, rural water access and rural sanitation, as well as increased public expenditure and total health care expenditure and an increased focus on education and training of health care professionals [54].

In Canada, the senior population made up $14.4 \%$ of the total Canadian population as of 2011 [55], indicating that a shift towards the community based model of health care comprising a smaller focus on hospitals and institutionalized short-term health care would be beneficial. The allotment of more resources towards long-term facilities over short-term care institutions will cater more closely to the needs of the aging population. Furthermore, long waiting times and hospital stays are frequently experienced by Canadians [56], and a larger investment into coverage of home care services would be beneficial. This would allow many services that are usually provided in hospitals, to be provided in outpatient settings instead, thereby serving to increase hospital space and more effectively address patient needs. Optimizing resource availability will ensure that individuals are able to address health care needs in a timely manner. This would be particularly beneficial to rural and Aboriginal communities, where significant shortages exist in health care accessibility due to a low physician to patient ratio. Additionally, the authors recommend a formalized form of information provision to be established, such as an online database relevant to patient education and decision-making accessible to all Canadians, as a preliminary step to providing the public with adequate information.

This review brings together a relatively disparate body of literature 
Citation: Agarwal A, Tofighi T, Chawla K, Mondal T (2013) Indian Versus Canadian Health Care Systems and Policy: A Review Based on Barr's Model of Health Care Governance. Health Care Current Reviews 1: 103. doi: 10.4172/2375-4273.1000103

Page 5 of 6

on the health care systems of India and Canada, drawing information from numerous sources and several mediums to provide a detailed overview of primary policies and mechanisms. Focusing on both health policy and federal health care administration, it assesses and compares attributes of the two systems. This is one of the first studies to carry out such a comparison within Barr's framework, a five-part model focused on health care education, regulation, financing, and delivery. The concepts discussed and methods applied here are widely-applicable to analysis of the health care governance mechanisms of other countries as well, opening avenues for future exploration. This unique and structured approach has ensured the collection of information relevant to several aspects of health care, and the development of a well-rounded analysis which integrates these different areas.

This study holds several limitations, particularly relevant to methodology. The unsystematic nature of this review and the lack of a definitive search strategy, screening, and extraction process may restrict the comprehensiveness of the analysis conducted. While the recommendations proposed are evidence-based, a more systematic approach would assist in providing more well-rounded and intricate suggestions relevant to the two systems. Furthermore, an integrated analysis of the role of health policy in shaping mechanisms associated with the five aspects of Barr's model between both countries would allow for a more holistic analysis; independent assessment of the prominent policies and the five aspects of Barr's model as conducted here may result in limitations in the scope of the findings and inferences discussed.

\section{Conclusion}

With visibly large differences in the balances of the two health care systems, different guiding national policies, and differences in the health care challenges faced by both countries, the health care systems of India and Canada present unique needs. Home to growing and changing populations, both India and Canada will undoubtedly experience challenges in prioritizing the required adjustments to their respective health care services that need to be made. As India struggles with optimizing health care services and increasing trust in the public sector, Canada's expensive system likewise struggles with addressing concerns regarding stability and meeting the needs of its aging population. However, the health care movement cannot begin with the government alone: there is greater potential for improvement with the continued positive support and push of the public. In this age, the particularly widespread availability and use of the Internet may play a role in raising public awareness in the near future, and this method of communication is essential towards inspiring the large scale health care movement that will help the advancement of medical care in India and Canada.

\section{Acknowledgment}

We would like to thank Dr. Harpreet Gill for review, editing and revision of the manuscript.

\section{References}

1. Naylor CD (1999) Health care in Canada: incrementalism under fiscal duress. Health Aff (Millwood) 18: 9-26.

2. Fuchs VR, Hahn JS (1990) How does Canada do it? A comparison of expenditures for physicians' services in the United States and Canada. N Engl J Med 323: 884-890

3. The Health of Canadians - The Federal Role, Final Report: Chapter Seventeen - The Canada Health Act (2013) Ottawa: Parliament of Canada.

4. Loh LC, Ugarte-Gil C, Darko K (2013) Private sector contributions and their effect on physician emigration in the developing world. Bull World Health Organ 91: 227-233.

5. Healthcare in India Emerging Market Report (2007) Price water house Coopers

6. Reinhardt UE, Hussey PS, Anderson GF (2004) US health care spending in an international context. Health Aff (Millwood) 23: 10-25.

7. Barr N (1993) The economics of the welfare state, (2ndedn), Stanford University Press, Stanford.

8. Understanding the Canada Health Act (2013) The Council of Canadians.

9. Bhat R (1998) Regulation of the private health sector in India. Int J Health Plann Manage 11: 253-274.

10. Annual Report to the People on Health (2012) New Delhi: Ministry of Health and Family Welfare.

11. India - 1. Trends in policy development (2007) World Health Organization Regional Office for South-East Asia.

12. Samandar R, Kleefield S, Hammel J, Mehta M, Crone R (2001) Privately funded quality health care in India: a sustainable and equitable model. Int $J$ Qual Health Care 13: 283-288.

13. Berman PA (1998) Rethinking health care system: private health care provision in India. World Dev 26: 1463-1479.

14. Deshpande K, RaviShankar, Diwan V, Lönnroth K, Mahadik VK, et al. (2004) Spatial pattern of private health care provision in Ujjain, India: a provider survey processed and analysed with a Geographical Information System. Health Policy 68: 211-222.

15. Bhat R (1993) The private/public mix in health care in India. Health Policy Plan 8: $43-45$.

16. Bhat $R$ (1999) Characteristics of private medical practice in India: a provider perspective. Health Policy Plan 14: 26-37.

17. Sullivan P (2012) Canada's MD/patient ratio improves but low international ranking continues. Ottawa: Canadian Medical Association.

18. Shetty P (2010) Medical tourism booms in India, but at what cost? Lancet 376 671-672.

19. Desai S, Sinha T, Mahal A (2011) Prevalence of hysterectomy among rural and urban women with and without health insurance in Gujarat, India. Reprod Health Matters 19: 42-51

20. Sengupta A, Nundy S (2005) The private health sector in India: Is burgeoning but at the cost of public health care. BMJ 331: 1157-1158

21. Berg E, Durgam R, Ramachandra M (2010) India's poor rely mainly onprivate health care. Oxford: University of Oxford CSAE Economics Department.

22. Schoen C, Osborn R, Doty MM, Bishop M, Peugh J, et al. (2007) Towards higher-performance health systems: adults' health care experiences in seven countries, 2007. Health Aff (Millwood) 26: 717-734

23. Wong A, Lohfeld $L$ (2008) Recertifying as a doctor in Canada: international medical graduates and the journey from entry to adaptation. Med Educ 42 53-60.

24. Schoen C, Osborn R, How SKH, Doty MM, Peugh J (2009) In chronic condition: experiences of patients with complex health care needs, in eight countries, 2008. Health Aff (Millwood) 28: 1-16

25. Sanmartin C, Shortt SED, Barer ML, Sheps S, Lewis S, et al. (2000) Waiting for medical services in Canada: lots of heat, but little light. CMAJ 162: 1305-1310.

26. Soroka SN (2007) Canadian perceptions of the health care system: A report to the Health Council of Canada. Toronto: Health Council of Canada.

27. Hutchison B, Abelson J, Lavis J (2001) Primary care in Canada: so much innovation, so little change. Health Aff (Millwood) 20: 116-131.

28. In health care, more is not always better (2013) Winnipeg: University of Manitoba. Evidence Network.

29. Health care system health indicators (2009) Ottawa: Health Canada.

30. Introduction (2013) New Delhi: Ministry of Health and Family Welfare

31. Duggal R, Nandraj S, Vadair A (1995) Special statistics-10: Health expenditure across states - Part 1. Economic and Political Weekly 30: 834-844. 
Citation: Agarwal A, Tofighi T, Chawla K, Mondal T (2013) Indian Versus Canadian Health Care Systems and Policy: A Review Based on Barr's Model of Health Care Governance. Health Care Current Reviews 1: 103. doi: 10.4172/2375-4273.1000103

Page 6 of 6

32. Peters DH, Muraleedharan VM (2008) Regulating India's health services: to what end? What future? Soc Sci Med 66: 2133-2144

33. Food and Drugs Act (2013) Ottawa: Government of Canada.

34. Munroe S (2013) British North America Act-BNA Act.

35. Romanow R (2002) Medically necessary: what is it, and who decides? Ottawa: Commission on the Future of Health Care in Canada.

36. Simon LI (2006) Health care financing policies of Canada, the United Kingdom and Taiwan. Hong Kong: Research and Library Services Division - Legislative Council Secretariat.

37. Indian public health standards (2006) New Delhi: Natural Rural Health Mission - Ministry of Health and Family Welfare.

38. Duggal R, Dilip TR, Raymus P (2005) Health and healthcare in Maharashtra: A status report. Mumbai: Centre for Enquiry into Health and Allied Themes.

39. Nandraj S (2001) Amendments to the Bombay Nursing Home Registration Act (1949): Existing provision and proposed changes. Mumbai: Department of Public Health - Government of Maharashtra.

40. Bloom G, Kanjilal B, Peters DH (2008) Regulating health care markets in China and India. Health Aff (Millwood) 27: 952-963.

41. Medi Smart and Save (2013) Canada Insurance Plan.

42. Deraspe R, Gauthier J (2011) Canada Health Transfer: Equal-per-capita cash by 2014. Ottawa: Library of Parliament of Canada.

43. Health care funding (2007) Canadian Health Care.

44. Makarenko J (2010) Canada's health care system: An overview of public and private participation. Maple Leaf Web.
45. Gangolli LV, Duggal R, Shukla A (2005) Review of healthcare in India. Mumbai: Centre for Enquiry into Health and Allied Themes.

46. Rashtriya Swasthya Bima Yogjna-About Us: About the Scheme (2009) Ministry of Labour and Employment.

47. Swarup A, Jain N (2011) Rashtriya Swasthya Bima Yojana, International Labour Organization.

48. Jeevandai Aarogya Yojana-About the Project/Scheme (2013) Pune: Government of Maharashtra Directorate of Health Services.

49. Chua K (2013) Canadian healthcare system fact sheet, American Medical Student Association.

50. World Health Organization SARO (2007) India: National health system profile New Delhi: World Health Organization - South-East Asia Regional Office.

51. De Costa A, Diwan V (2007) 'Where is the public health sector?' Public and private sector healthcare provision in Madhya Pradesh, India. Health Policy 84: 269-276.

52. Weinstein ND (1989) Optimistic biases about personal risks. Science 246 1232-1233.

53. Thakur JS (2011) Key Recommendations of High-Level Expert Group Report on Universal Health Coverage for India. Indian J Community Med 36: 84-85.

54. Faster, Sustainable and More Inclusive Growth: An Approach to the Twelfth Five Year Plan (2011) New Delhi: Government of India Planning Commission.

55. Canadians in Context-Aging Population (2013) Ottawa: Human Resources and Skills Development Canada.

56. Canadians still waiting too long for health care: Report Card on Wait Times in Canada (2013) Wait Time Alliance. 